\title{
SELECTION OF REFERENCE VALUE OF LONGITUDINAL TO TRANSVERSAL ULTRASONIC WAVES VELOCITY RATIO ON PRESSURE PURPOSE STEELS FOR DETECTION OF CREEP
}

\author{
TOMÁŠ ZAVADIL ${ }^{a, b}$ \\ a Advanced Technology Group, s.r.o., Toužimská 771, 199 02 Prague, Czech Republic \\ ${ }^{b}$ Department of Materials, Faculty of Nuclear Sciences and Physical Engineering, Czech Technical University in \\ Prague, Trojanova 13, 12001 Prague, Czech Republic \\ correspondence: zavadilt@atg.cz
}

\begin{abstract}
Common degradation process for industrial equipment in power and petrochemical industry is creep. The ultrasonic waves velocities and their ratio can provide feedback on stress-strain conditions generated by heat. Selection of potentially critically affected parts of pressure equipment can be theoretically accessed by their means. Selection of such critical parts or areas is done by comparison with reference benchmark value. Setting the standard reference value for conventional pressure purpose steel is crucial so it can be later used as a benchmark for selection of critical areas on equipment under operation. The article proposes a benchmark value to be utilized for P265GH pressure purpose steel and steels of similar grade.
\end{abstract}

KEYWORDS: Residual stress, non-destructive testing, ultrasonic testing, creep.

\section{INTRODUCTION}

Creep is one of the main phenomena responsible for the failure of plant pressure equipment operating at elevated temperatures. Creep is associated with the synergistic effect of changes of microstructure and strain accumulation, which leads to nucleation, growth and coalescence of microvoids, and subsequently to component failure. Extending the service life of major components is crucial in high temperature plant applications. The life expectancy is based on the ability of the material to retain its high-temperature creep strength for period of at least twice the projected design life. Development of new methods that shall be able to assess the material condition is therefore necessary [1]. Various non-destructive testing techniques have been developed to detect the creep damage. Techniques range from acoustic emission, infrared thermography, ultrasonic attenuation and velocity measurements, acoustic harmonic measurements up to eddy currents [2, 3].

Acousto-elastic and acousto-plastic effects are responding to stress in elastically deformed body and to residual stresses created by macroscopic deformation. Most of residual stresses are induced by plastic strain. Creep is a long-time plastic deformation of equipment subject to heat and pressure, therefore acoustic measurements of residual stresses are suitable candidate for the proposed application for detection of creep degradation process.

In order to measure the response to creep degradation process it is necessary to measure the stress values itself, or compare individual measurements suspected from creep to a reference benchmark value for unaffected material. The following article is dealing with setting of this reference benchmark value.

\section{Stress Measurement By Conventional Ultrasonic TESTING}

The ultrasonic waves velocity is a function of stress $\sigma$ as described by Obraz [4]. Example of a simple uniaxial stress measurement in a bar may be written as follows:

$$
\sigma=\frac{\delta t-\left(\beta_{T}+\alpha_{T}\right) \Delta T}{\beta_{\sigma}+\frac{1}{\epsilon}}
$$

where $\delta t=\Delta t / t_{0}$ is fractional change in time of flight (TOF), $\alpha_{T}$ and $\beta_{T}$ are coefficients of heat expansion, $\Delta T$ is change of temperature and $\beta_{\sigma}$ is acoustoelastic coefficient and $\epsilon$ is the fractional change in length.

If the $\Delta T \rightarrow 0$ (there is no significant temperature change), the formula can be simplified as:

$$
\sigma=\frac{\delta t}{\beta_{\sigma}+\frac{1}{\epsilon}}
$$

We may use the TOF of either longitudinal ultrasonic waves or transversal waves. Putting the TOF values to a ratio, the situation further transforms to:

$$
\sigma=\frac{\frac{t_{0 T}}{t_{0 L}}-\frac{t_{T}}{t_{L}}}{\left(\beta_{\sigma L}+\frac{1}{\epsilon}\right)\left[\frac{t_{0 T}}{t_{0 L}}+\frac{t_{T}}{t_{L}}\right]}
$$

where $t_{0 T} / t_{0 L}$ is TOF ratio on tested part before applied loading and $t_{T} / t_{L}$ after the applied loading. This formula, however, is difficult to use during inservice inspections for the following reasons: 
(1.) The equipment's original state is not available for comparison.

(2.) The fractional change of length $\epsilon$ cannot be calculated as the precise dimensions may not be known.

(3.) The stress in operated equipment is rather multiaxial than uniaxial, especially when considering creep-induced strengthening.

Therefore despite the ultrasonic waves velocity (and respective TOF) are changed due to the induced residual stress, it cannot be measured directly. This implies that precise measurement of stress $\sigma$ cannot be used and ordinal means of evaluation (i.e. comparison of tested area with (a set of) reference samples) for detection of critical areas is the only option.

The ultrasonic waves velocities for generally anisotropic material of the tested part are given (as proposed by According to Schneder and Goebbels [5]) as follows:

$$
\begin{gathered}
c_{z z}=\sqrt{\frac{\lambda+2 \mu+(2 l+\lambda) \xi+(4 m+4 \lambda+10 \mu) \epsilon_{z}}{\rho}} \\
c_{z x}=\sqrt{\frac{\mu+(\lambda+m) \xi+4 \mu \epsilon_{z}+2 \mu \epsilon_{x}-0.5 n \epsilon_{y}}{\rho}} \\
c_{z y}=\sqrt{\frac{\mu+(\lambda+m) \xi+4 \mu \epsilon_{z}+2 \mu \epsilon_{y}-0.5 n \epsilon_{x}}{\rho}}
\end{gathered}
$$

where $c_{i j}$ is ultrasonic waves velocity in plain $i j, \rho$ is density, $\epsilon_{i}$ is strain in the given axis, $\xi=\epsilon_{x}+$ $\epsilon_{y}+\epsilon_{z}, \lambda$ and $\mu$ are Lamé's constants, and $l, m, n$ are Murnaghan's constants. Young modulus $E$ and shear modulus $G$ are linked with Lamé's constants as described in the formula below:

$$
E=\frac{\nu(3 \lambda+2 \mu)}{\lambda+\mu} ; \quad G=\mu
$$

where $\nu$ is Poisson's ratio. Assuming the tested volume of the tested part has isotropic behavior (i.e. the material properties are not changing with directions) and using the abovementioned formula (5), the equations for longitudinal and transversal waves velocity (4) may be then further simplified to the following:

$$
\begin{aligned}
c_{L} & =\sqrt{\frac{E}{\rho} \frac{1-\nu}{(1+\nu)(1-2 \nu)}} \\
c_{T} & =\sqrt{\frac{G}{\rho}}=\sqrt{\frac{E}{\rho} \frac{1}{2(1+\nu)}}
\end{aligned}
$$

where $E$ is Young modulus, $G$ is shear modulus, $\rho$ is density and $\nu$ is Poisson's ratio.

The common observation is that the longitudinal waves velocity $c_{L}$ increases with applied load in elastic region while the transversal waves velocity decreases. As was experimentally confirmed by the team from Det Norske Veritas [6], the increase of velocity of the longitudinal waves is limited and when it reaches a critical level of strain, it starts to decrease again. Similar result was observed also for transversal waves by Kobayashi [7] where the velocity decreases in elastic region, while in the plastic region it again increases. The behavior was described as being a consequence of anisotropy in elastic properties and inhomogeneous localization of plastic strain [8,9]. Such may include creation of point defects, slip bands and yield vertex which is responsible for degradation of elastic modulus.

The inverse behavior of longitudinal and transversal waves' velocity may be used advantageously when observed as a ratio of both values, i.e. $c_{L} / c_{T}$ (also $L / T$ ratio, dimensionless). The problem can be then transformed to a single-variable equation (only variable is the Poisson's ratio) with monotone-increasing features:

$$
\frac{c_{L}}{c_{T}}=\sqrt{\frac{E}{\rho} \frac{1-\nu}{(1+\nu)(1-2 \nu)}} \sqrt{\frac{\rho}{G}}=\sqrt{\frac{2(1-\nu)}{1-2 \nu}}=f(\nu)
$$

This can help to determine the current stress/strain relation as was observed by Kumar et al. [10] in their article about correlation of transversal (and longitudinal) wave velocity and Poisson's ratio.

Young and shear modulus tend to vary in the same direction in any metal material. This implies that the variation of the Poisson's ratio is dependent only on how much each of the moduli will be affected. Let's assume the range of Poisson's ratio is practically bound to $0<\nu<0.5$ (for isotropic solids) [11]. The higher the ratio the less volume change during deformation, where $\nu=0.5$ means no volume change.

Plot of the abovementioned part of the equation (7) is on Fig. 1 . Poisson's ratio as $\nu=0.25 \div 0.30$ is a common value for conventional structural steels and similar, so this provides preliminary expected range of $L / T$ ratio values of $c_{L} / c_{T}=1.73 \div 1.87$.

\section{Effect of CReep on $L / T$ Ratio VALUES}

Ongoing research of the author 13 performed measurements on collapsed membrane wall from P265GH pressure purpose steel that was subject to creep rupture. The observed results concluded the it was shown that the $L / T$ ratio is sensitive to plastic deformation due to strengthening mechanisms and is able to detect areas exposed to tension or compression due to bending as well as plastic deformation due to combined effect of internal pressure and heat.

The values of $L / T$ ratio in this experiment proven to be in range of $1.80 \div 1.85$ in measurement spots far from the area affected by creep. The values were growing from the reference value towards its maximum of 2.086 located on the crack edge from all directions. The affected area of elevated $L / T$ ratio values was $<50 \mathrm{~mm}$ from the crack edge. The key results are shown in Fig. 2.

From the Fig. 2 it can be assumed that the 1.85 might be the benchmark reference value for P265GH 


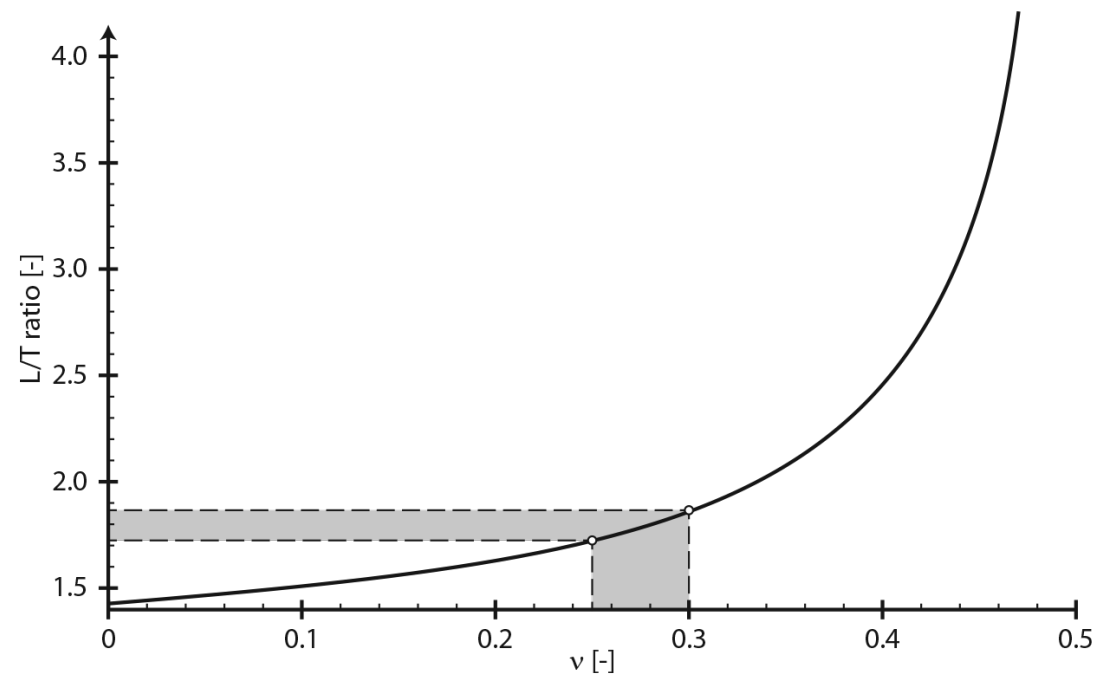

Figure 1. $c_{L} / c_{T}$ as a function of the Poisson's ratio $\nu$ for isotropic continuum. The selected area of values common for structural steels $(\nu=0.25 \div 0.30)$ provides expected range of $c_{L} / c_{T}=1.73 \div 1.87$ [12].
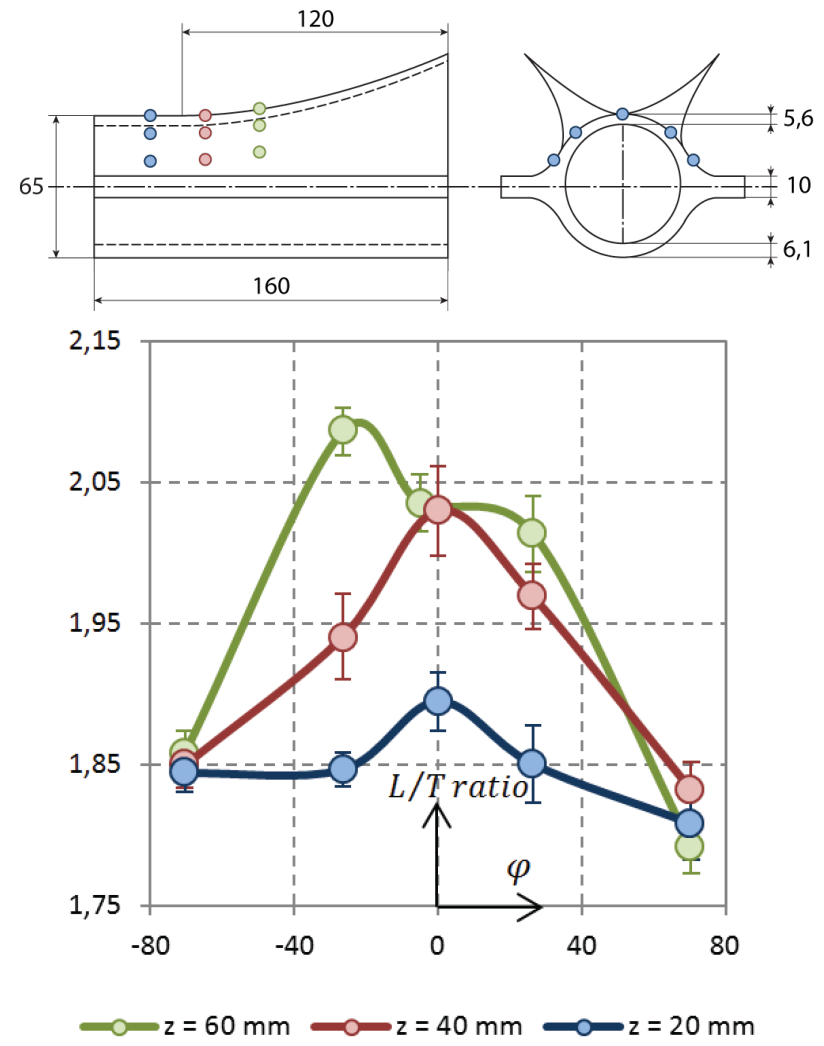

Figure 2. Sample subject to creep rupture with measured values of $L / T$ ratio along the planes $\mathrm{R} 1$ (blue), R2 (red) and R3 (green). Connecting lines in the charts DO NOT provide any physical relation or a trend, they are for better orientation only [13. grade pressure purpose steel. If the premise is accepted, the elevated values of 2.086 were above the $3 \mathrm{~s}$ (3 standard deviations) of the assumed benchmark value and therefore the elevated values should be considered as relevant and referring about non-standard stress-strain conditions, potentially caused by a degradation process as creep (the type degradation process is assumed due to knowledge of the history of operation of the particular tested part).

The following part of the article focuses on finding a standard benchmark value for unaffected material (i.e. non-degraded) and therefore proving the abovementioned assumption is justifiable.

\section{Experimental Setup}

The experiment intends to find expected value that can be used as a standard global benchmark value of the $L / T$ ratio measured on pressure purpose steel that is not subject to long-time processes causing high residual stresses. A set of steels with similar chemical composition (to each other as well as to the original P265GH steel) and different levels of heat treatment have been tested and mutually compared. The each of the following:

(1.) expected value and standard deviation of each of the steels,

(2.) value trend based on chemical composition and heat treatment,

(3.) and range of values for the whole steel group,

shall then help determining what are the benchmark $L / T$ ratio values as well as what are the values that might be already considered as caused by severe degradation processes.

If the values will be in controlled range for unaffected steel (i.e. standard deviation of $L / T$ ratio values for samples with the same carbon content but various heat treatment shall be low), it can be assumed 
that the $L / T$ ratio has material- and heat-treatmentspecific values. That would imply a significant change of material properties due to long exposure to heat is measurable, and clearly distinguishable from unaffected material.

For this experiment, the level of $L / T$ ratio considered as out of standard value range shall be defined as:

$$
\Delta \frac{c_{L}}{c_{T}}=\Delta \frac{c_{L}}{c_{T}}(\sigma)>3 s ; \quad \sigma \gg \sigma_{0}
$$

or more precisely:

$$
\begin{aligned}
& \Delta \frac{c_{L}}{c_{T}}(\sigma)>3 \cdot \max _{j}\left\{s_{j}\right\}= \\
= & 3 \cdot \max _{j} \sqrt{\frac{1}{N-1} \sum_{i=0}^{N_{j}}\left(\frac{c_{L}}{c_{T_{i}}}-\left\langle\frac{c_{L}}{c_{T}}\right\rangle_{j}\right)^{2} ;} \quad \sigma \gg \sigma_{0}
\end{aligned}
$$

where $s_{j}$ is the standard deviation of the steel $j, N_{j}$ is the number of measurements for the benchmark value of steel $j,\left\langle c_{L} / c_{T}\right\rangle$ is the average mean value of the all steel types, $\sigma_{0}$ a generally unknown stress level of steel that is not subject to longtime exposure to heat and $\sigma$ is a stress of affected (exposed, degraded) volume. The result shall be compared with the expected result acc. to Fig. 1] where it should fit the expected range of values $1.73 \div 1.87$.

\subsection{SAMPLES}

Samples subject to the experiment were short bars with a length of $20 \mathrm{~mm}$ and various diameter up to $20 \mathrm{~mm}$. Samples were from three types of standard structural steel (C16E/1.1148, C35/1.0501, C55/1.0535) heat treated in a laboratory conditions for 2 quenching temperatures $T_{Q}\left(850{ }^{\circ} \mathrm{C}\right.$ and $\left.950^{\circ} \mathrm{C}\right)$ and 4 various tempering temperatures $T_{T}\left(400^{\circ} \mathrm{C}\right.$, $500^{\circ} \mathrm{C}, 600^{\circ} \mathrm{C}$, and $700^{\circ} \mathrm{C}$ ) for one hour. The samples were in totally 24 sets and each set of samples had between 4 and 5 samples. The selected steel types were similar in the chemical composition to the conventional P265GH pressure purpose steel [12]. The closest steel (by chemical composition) to P265GH was C16E, other steels had mainly higher carbon content, which assumes different (higher) standard values for the $L / T$ ratio. The heat-treatment processings were selected to simulate maximal structural changes that are not caused by extreme degradation processes (i.e. mainly phase transform and recrystallization effects).

\subsection{EQUIPMENT}

Measurement was performed on Sonatest Sitescan $250 s$ by ultrasonic pulse-echo technique. The standard ultrasonic testing (UT) equipment was selected on purpose to 1) simulate standard in-service inspection options of measurement and 2) to fit the measurement with analysis done on collapsed membrane wall in experiment briefly described in chapter 3 The time of flight (TOF) was measured directly on the device and it was recalculated to ultrasonic waves' velocity. Conventional direct UT probes Sonatest RDT2550 with peak frequency $4.64 \mathrm{MHz}$ for longitudinal waves and Panametrics V155 with peak frequency of $4.25 \mathrm{MHz}$ for transversal waves were used. Measurement areas were flat, with smooth surface and without any corrosion products that may affect the measurement. The precise thickness was measured by a micrometer.

\section{Results}

\section{GeneraL}

The measured values were well controlled with $L / T$ ratio in the range of $c_{L} / c_{T}=1.812 \div 1.835$. The average $L / T$ ratio was $\left\langle c_{L} / c_{T}\right\rangle=1.82$. The maximal nominal value as well as standard deviation $s$ for the measurements was $\max _{j}\left\{s_{j}\right\}=0.005$ for $j$ equal to steel C55 quenched on $T_{Q}=950{ }^{\circ} \mathrm{C}$, which was fully phase transformed to martensitic structure.

\section{STEEL C16E}

Steel C16E/1.1148 is by chemical composition closest to the P265GH steel. Compared to the other groups it has the lowest amount of carbon $\mathrm{C}$ and higher average of Manganese Mn. Values of the $L / T$ ratio for this steel have the average of $\left\langle c_{L} / c_{T}\right\rangle_{C 16 E \mid 850}=$ $1.816 \pm 0.001$ for group quenched on $T_{Q}=850^{\circ} \mathrm{C}$ and $\left\langle c_{L} / c_{T}\right\rangle_{C 16 E \mid 950}=1.819 \pm 0.001$ for group quenched on $T_{Q}=950^{\circ} \mathrm{C}$. The values are virtually almost constant with changing tempering temperature $T_{T}$.

\section{STEEL C35}

Steel C35/1.0501 has the average amount of carbon $\mathrm{C}$ and lower average of Manganese Mn. Values of the $L / T$ ratio have the average of $\left\langle c_{L} / c_{T}\right\rangle_{35 \mid 850}=$ $1.816 \pm 0.002$ for group quenched on $T_{Q}=850^{\circ} \mathrm{C}$ and $\left\langle c_{L} / c_{T}\right\rangle_{35 \mid 950}=1.819 \pm 0.003$ for group quenched on $T_{Q}=950^{\circ} \mathrm{C}$. The values have monotonously decreasing trend with increasing tempering temperature $T_{T}$.

\section{STEEL C55}

Steel C55/1.0535 compared to the other groups has the maximal amount of carbon $\mathrm{C}$ and lower average of Manganese Mn. Values of the $L / T$ ratio have the average of $\left\langle c_{L} / c_{T}\right\rangle_{C 55 \mid 850}=1.821 \pm 0.003$ for group quenched on $T_{Q}=850^{\circ} \mathrm{C}$ and $\left\langle c_{L} / c_{T}\right\rangle_{C 55 \mid 950}=$ $1.826 \pm 0.005$ for group quenched on $T_{Q}=950^{\circ} \mathrm{C}$. The values have monotonously decreasing trend with increasing tempering temperature $T_{T}$.

\section{Chemical COMPosition, TEMPERING AND QUENCHING EFFECT}

General trends were observable on the charts of measured values. The measured $L / T$ ratio values were:

- the higher the higher is the concentration of carbon $\mathrm{C}$ (see Fig. 5),

- the higher the lower is the tempering temperature $T_{T}$ (see Fig. 4, 


\begin{tabular}{lcccccccc}
\hline Steel type & $\mathbf{C}[\%]$ & $\mathbf{M n}[\%]$ & $\mathbf{S i}[\%]$ & $\mathbf{C r}[\%]$ & $\mathbf{N i}[\%]$ & $\mathbf{C u}[\%]$ & $\mathbf{P}[\%]$ & $\mathbf{S}[\%]$ \\
\hline $\mathbf{C 1 6 E} / \mathbf{1 . 1 1 4 8}$ & $>0.13$ & $>0.60$ & $>0.15$ & $<0.25$ & $<0.30$ & $<0.30$ & $<0.04$ & $<0.04$ \\
$($ ČSN 412020) & $<0.20$ & $<0.90$ & $<0.40$ & & & & & \\
\hline $\mathbf{C 3 5} / \mathbf{1 . 0 5 0 1}$ & $>0.30$ & $>0.50$ & $>0.15$ & $<0.25$ & $<0.30$ & $<0.30$ & $<0.04$ & $<0.04$ \\
$($ ĆSN 412040) & $<0.40$ & $<0.80$ & $<0.40$ & & & & & \\
\hline $\mathbf{C 5 5} / \mathbf{1 . 0 5 3 5}$ & $>0.52$ & $>0.50$ & $>0.15$ & $<0.25$ & $<0.30$ & $<0.30$ & $<0.04$ & $<0.04$ \\
$($ ČSN 412060) & $<0.60$ & $<0.80$ & $<0.40$ & & & & & \\
\hline
\end{tabular}

TABlE 1. Chemical composition of the steel group used for test samples (composition acc. to Czech standards ČSN 412020, ČSN 412040 and ČSN 412060).
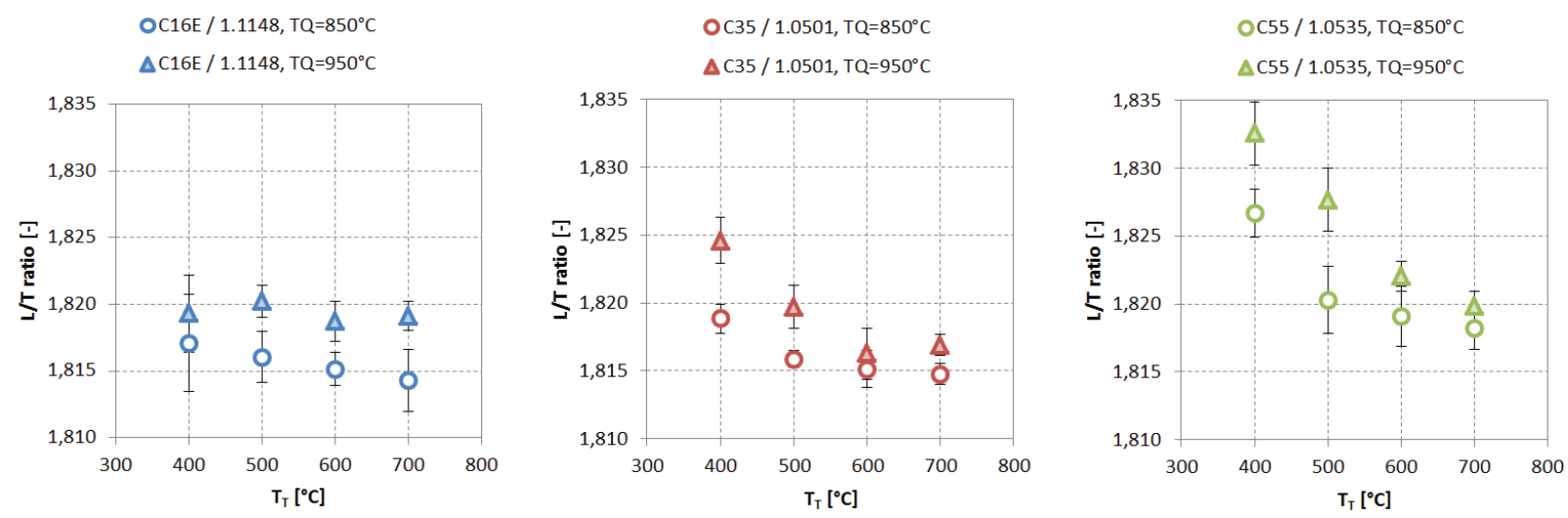

Figure 3. Measured $L / T$ ratio values grouped by steel type. C16E (blue), C35 (red) and C55 (green). Values for quenching temperatures $T_{Q}=850^{\circ} \mathrm{C}$ (circle) tend to be in all cases lower than for $T_{Q}=950^{\circ} \mathrm{C}$ (triangle).

- higher for higher quenching temperature $T_{Q}$ (see Fig. 33).

For quenching temperature of $T_{Q}=850^{\circ} \mathrm{C}$ the values across the chemical composition range shown smaller standard deviation $(\max s=0.042 \%)$ and across the tempering temperature higher standard deviation ( $\max s=0.163 \%$ ). For the quenching temperature $T_{Q}=950^{\circ} \mathrm{C}$ the values increased to $0.054 \%$ for $T_{Q}=850{ }^{\circ} \mathrm{C}$ and $0.243 \%$ for $T_{Q}=950{ }^{\circ} \mathrm{C}$ respectively.

\section{Discussion}

Values of the $L / T$ ratio during the experiment on conventional structural steels C16E, C35 and C55 were well controlled within range of $1.812 \div 1.835$. These steels (especially C16E) were selected for their similarity with to P265GH conventional pressure purpose steel. Minimal values were observed in general for low carbon content and low quenching temperatures. The values were changing by heat-induced structural changes and induced phase transformation. That is logical, because they may be a source of a creation and/or change of residual stress. Such can be measured by the ultrasonic waves velocity changes or changes of its ratio as explained in chapter 2 A simple relation between the $L / T$ ratio and e.g. the heat treatment temperature however may not be drawn. The reason is that a minimal temperature may be needed to introduce change of stress-strain conditions (i.e. by phase transform etc.). It is expected the $L / T$ ratio as a function of temperature may be only semi-continuous and may include occasional sudden leaps.

This phenomena can be demonstrated on samples with higher carbon content and nominal quenching temperature $\left(\mathrm{C} 55, T_{Q}=950^{\circ} \mathrm{C}\right)$. Higher quenching temperature well above Ac3 ensures full phase transformation. Higher carbon content opens the TTT (timetemperature-transformation) diagram and pushes the $B_{S}$ (Bainite start) curve to longer times. Original $\alpha-\mathrm{Fe}$ is transformed to $\gamma-\mathrm{Fe}$ and then back with creation of martensitic or martensitic-bainitic structure. Low tempering temperature does not break the created martensitic and/or bainitic structure and has minimal impact. Because the martensitic phase transformation is accompanied with applied stress from the lattice, the highest $L / T$ ratio values can be found there $\left(\left\langle c_{L} / c_{T}\right\rangle_{C 55 \mid 950}=1.833 \pm 0.002\right)$.

Other side of the spectra of provided samples represents steel $\mathrm{C} 16 \mathrm{E}$, which has the lowest carbon content and is quenched on temperature $T_{Q}=850^{\circ} \mathrm{C}$, i.e. under Ac3 curve. It can be expected to observe lower $L / T$ ratio numbers. The phase transformation is only partial $\left(A 1<T_{Q}<A c 3\right)$ and low carbon content pushes the TTT diagram closer to short times, which makes the cooling speed too slow to create purely martensitic structure. Additional tempering, especially on higher temperatures, i.e. $600^{\circ} \mathrm{C}$ and more tends to create sorbitic structure. Such process re- 

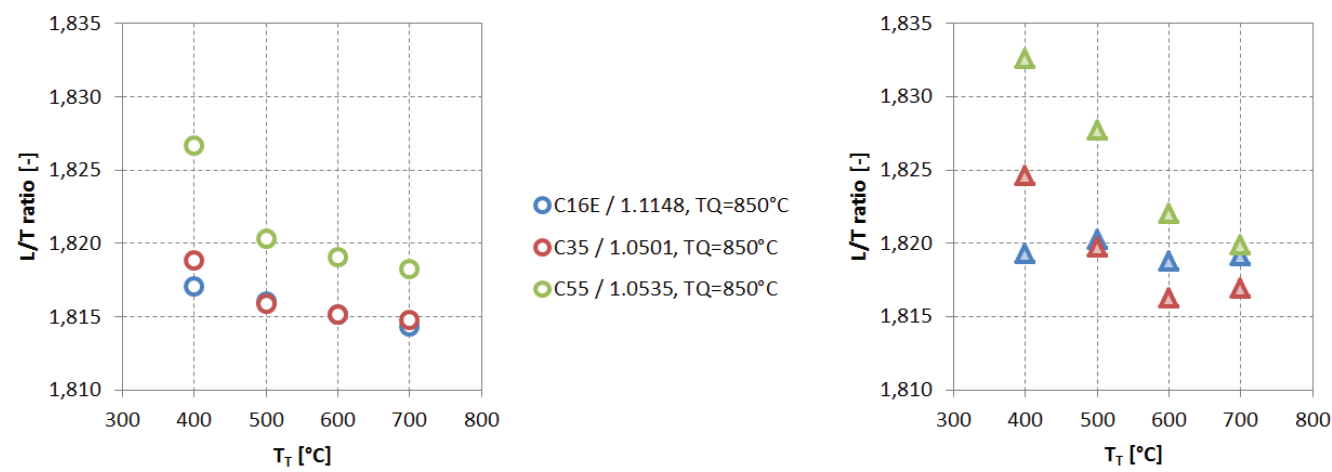

$\triangle \mathrm{C} 16 \mathrm{E} / 1.1148, \mathrm{TQ}=950^{\circ} \mathrm{C}$

OC16E $/ 1.1148, \mathrm{TQ}=850^{\circ} \mathrm{C}$ OC35 $/ 1.0501, T Q=850^{\circ} \mathrm{C}$ OC55 $/ 1.0535, T Q=850^{\circ} \mathrm{C}$ $\triangle \mathrm{C} 35 / 1.0501, \mathrm{TQ}=950^{\circ} \mathrm{C}$ $\triangle \mathrm{C} 55 / 1.0535, \mathrm{TQ}=950^{\circ} \mathrm{C}$

Figure 4. Measured $L / T$ ratio values grouped by quenching temperatures. C16E (blue) had in general the lowest $L / T$ ratio values, C35 (red) average and C55 (green) the highest for both quenching temperatures $T_{Q}=850{ }^{\circ} \mathrm{C}$ (circle) and $T_{Q}=950^{\circ} \mathrm{C}$ (triangle).
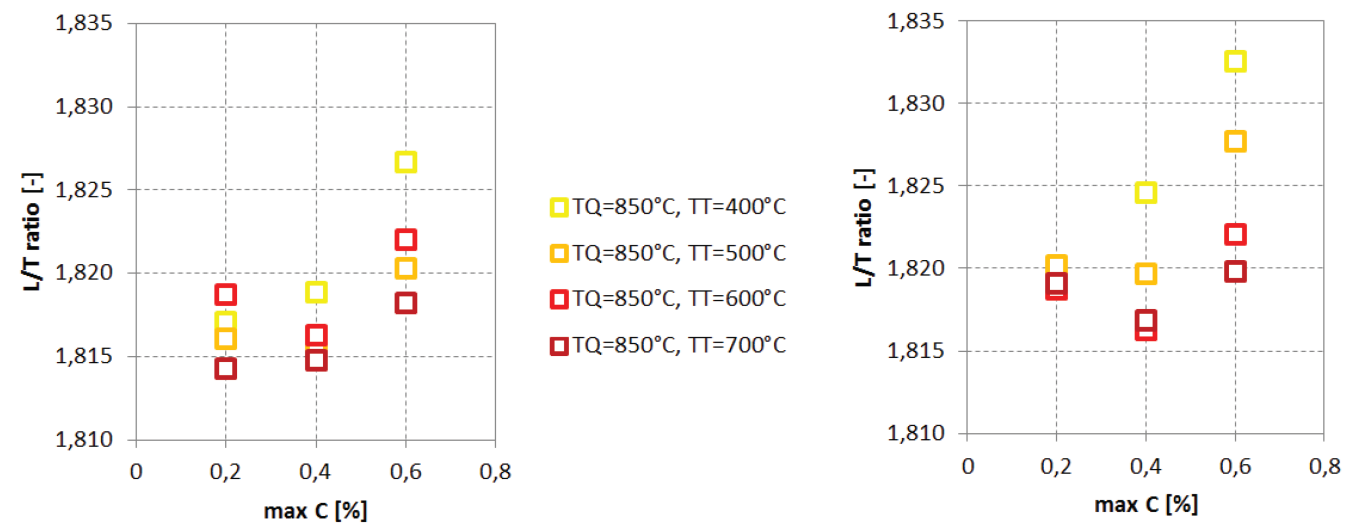

$\square \mathrm{TQ}=950^{\circ} \mathrm{C}, \mathrm{T}=400^{\circ} \mathrm{C}$

$\mathrm{TQ}=850^{\circ} \mathrm{C}, \mathrm{T}=400^{\circ} \mathrm{C}$

TQ $=850^{\circ} \mathrm{C}, \mathrm{TT}=500^{\circ} \mathrm{C}$

$\mathrm{QTQ}=850^{\circ} \mathrm{C}, \mathrm{TT}=600^{\circ} \mathrm{C}$

$\mathrm{\square TQ}=850^{\circ} \mathrm{C}, \mathrm{T}=700^{\circ} \mathrm{C}$

$\square \mathrm{TQ}=950^{\circ} \mathrm{C}, \mathrm{T}=500^{\circ} \mathrm{C}$

口TQ $=950^{\circ} \mathrm{C}, \mathrm{TT}=600^{\circ} \mathrm{C}$

口TQ $=950^{\circ} \mathrm{C}, \Pi=700^{\circ} \mathrm{C}$

Figure 5. Measured $L / T$ ratio values grouped by tempering temperatures. The $L / T$ ratio values decreased for with increasing tempering temperature for all, $\mathrm{C} 16 \mathrm{E}(\max \mathrm{C}=0.2 \%), \mathrm{C} 35(\max \mathrm{C}=0.4 \%)$ and $\mathrm{C} 55(\max \mathrm{C}=0.6 \%)$ and quenching temperatures $T_{Q}=850^{\circ} \mathrm{C}$ (left) and $T_{Q}=950{ }^{\circ} \mathrm{C}$ (right).

lieves the residual stresses and the $L / T$ ratio is in range of $\left\langle c_{L} / c_{T}\right\rangle_{C 16 E \mid 850}=1.816 \pm 0.001$.

All other measurements were in between of those two extremes. The experimental results fitted to the calculated range of $c_{L} / c_{T}=1.73 \div 1.87$ in chapter 2 for structural steels as was originally expected.

The $\mathrm{C} 16 \mathrm{E}$ had the most similar chemical composition of the test samples to $\mathrm{P} 265 \mathrm{GH}$ conventional pressure purpose steel. This steel is used for production of e.g. membrane walls and first level superheaters. The first approximation of expected value for the P265GH steel unaffected by large-scale heat effect or creep process should be close to the value of this (C16E) steel. Expected range acc. to equation (9) and the reference (benchmark) value can be calculated as follows:

$$
\begin{aligned}
\left\langle\frac{c_{L}}{c_{T}}\right\rangle_{P 265 \mid R E F} & =\left\langle\frac{c_{L}}{c_{T}}\right\rangle_{j} \pm \\
& \pm 3 \cdot \max _{j} \sqrt{\frac{1}{N-1} \sum_{i=0}^{N_{j}}\left(\frac{c_{L}}{c_{T_{i}}}-\left\langle\frac{c_{L}}{c_{T}}\right\rangle_{j}\right)^{2}}
\end{aligned}
$$

where $j$ is referring to the set of samples of $\mathrm{C} 16 \mathrm{E}$ with $T_{Q}=850^{\circ} \mathrm{C}$. If the value are filled:

$$
\left\langle\frac{c_{L}}{c_{T}}\right\rangle_{P 265 \mid R E F}=1.817 \pm 3 \cdot 0.004=1.817 \pm 0.012
$$

where $\left\langle\frac{c_{L}}{c_{T}}\right\rangle_{P 265 \mid R E F}$ is the reference (benchmark) value range for unaffected $\mathrm{P} 265 \mathrm{GH}$ steel. Notice that the $3 s$ is only $0.7 \%$ of the average value. This means the measurement of unaffected steel should be very precise and easily separable from measurements from affected material.

The samples subject to severe strengthening shall have values significantly higher than the maximal reference value range. This means the values expected for affected material should fulfill the formula $\left\langle\frac{c_{L}}{c_{T}}\right\rangle_{P 265 \mid T E S T} \gg\left\langle\frac{c_{L}}{c_{T}}\right\rangle_{P 265 \mid R E F}^{\max }=1.829$. Measurements performed on collapsed membrane wall from P265GH pressure purpose steel as described in chapter 3 found maximal values of $L / T$ ratio peaking to $\left\langle\frac{c_{L}}{c_{T}}\right\rangle_{P 265 \mid T E S T}^{\max }=2.086$ close to the crack tip as visible on Fig. 2 13. That is a value $14 \%$ higher than the reference value (it is also 67 times the standard deviation $s_{C 16 E \mid 850}$, see formula $(10)$ ). It is therefore obvious that severe changes of stress-strain conditions can be clearly separable from the provided reference 
value. Such changes may be caused by creep, but also other processes, that impact local stress level in the material.

\section{Conclusion}

The goal of this article was to find expected benchmark reference value of ratio of longitudinal and transversal ultrasonic waves velocities ( $L / T$ ratio) for detection of creep degradation process on conventional non-alloyed pressure purpose steel (e.g. P265GH). The article demonstrates that the $L / T$ ratio is usable method of detection of creep-induced strengthening be measuring induced stress. The performed experiment on three types of structural steel (C16E, C35 and C55) found that the values of $L / T$ ratio are well controlled around the value of 1.82 (dimensionless) for material not subject to degradation and do not drop below 1.812 or raise above 1.835 . This is in agreement with computed expected results with range of $c_{L} / c_{T}=1.73 \div 1.87$ for steels with Poisson's ratio $\nu=0.25 \div 0.30$.

Similarity of C16E structural steel with P265GH pressure purpose steel (steel used for production of membrane walls, first level superheaters etc.) was used to calculate a first level approximation of reference benchmark value range for non-degraded P265GH steel with value $\left\langle\frac{c_{L}}{c_{T}}\right\rangle_{P 265 \mid R E F}=1.817 \pm 0.012$. Due to the strengthening mechanisms the upper bond of the reference value $\left\langle\frac{c_{L}}{c_{T}}\right\rangle_{P 265 \mid R E F}^{\max }=1.829$ is a benchmark for comparison with potentially degraded material.

Comparison with results measured on collapsed membrane wall from P265GH subject to creep rupture also confirmed the reference value being accurate. It was observed that creep-induced strengthening is both measurable and clearly distinguishable from the reference value, with peak value $\left\langle\frac{c_{L}}{c_{T}}\right\rangle_{P 265 \mid T E S T}^{\max }=2.086$.

In conclusion the article proved there is a materialand heat-treatment-specific reference benchmark value that can be used for detection of structural changes of the material through change of its stress-strain conditions. The evaluation of degradation process by this means is expected to be ordinal (comparison with a set of reference samples). Such application may be used in case of e.g. on-site RLA inspections. Continuation of the research will now focus on simplification of the measurement process for on-site inspections and verification of ability to detect the degradation process in its early stages.

\section{ACKNOWLEDGEMENTS}

This article is based on author's bachelor's degree thesis and is a part of ongoing postgraduate studies on Czech Technical University in Prague, Faculty of Nuclear Sciences and Physical Engineering. Valuable discussions with Mr. Jaroslav Pitter (materials and corrosion specialist, thesis advisor), colleagues from the ATG, Ltd., Mr. Petr Žbánek (UT L3), Mr. Jiří Blahušek (UT L3), Mr. Jan Švub (RLA inspector) and the professor Jiří Kunz from the Department of Materials, Faculty of Nuclear Sciences and Physical Engineering, CTU in Prague, are gratefully acknowledged. This article is a derivative based on a presentations held on the student conference Šimáně 2018 and 57th BINDT conference in Birmingham including respective Books of Proceedings.

\section{REFERENCES}

[1] V. Sklenička, K. Kuchařová, M. Svoboda, et al. Long-term creep behavior of 9-12\% Cr power plant steels. Materials Characterization 51(1):35 - 48, 2003. DOI:10.1016/j.matchar.2003.09.012

[2] S. Baby, B. N. Kowmudi, C. Omprakash, et al. Creep damage assessment in titanium alloy using a nonlinear ultrasonic technique. Scripta Materialia 59(8):818 821, 2008. DOI:10.1016/j.scriptamat.2008.06.028.

[3] G. Sposito, C. Ward, P. Cawley, et al. A review of nondestructive techniques for the detection of creep damage in power plant steels. NDTEE International 43(7):555 567, 2010. DOI:10.1016/j.ndteint.2010.05.012

[4] J. Obraz. Zkoušení materiálu ultrazvukem. SNTL.

[5] E. Schneider, V. Goebbels. VDI-Berichte No. 439.

[6] S. Eldevik, A. A. F. Olsen, P. Lunde. Sound velocity change owing to the acoust-elastic/plastic effect in steel measured using acoustic resonance technology (art). In Scandinavian Symposium on Physical Acoustics, Geilo, Jan 29th - Feb 1st.

[7] M. Kobayashi. Acoustoelastic theory for plastically deformed solids. JSME international journal Ser 1, Solid mechanics, strength of materials 33:310-318, 1990. DOI:10.1299/jsmea1988.33.3_310

[8] M. Kobayashi. Ultrasonic nondestructive evaluation of microstructural changes of solid materials under plastic deformation-part i. theory. International Journal of Plasticity 14(6):511 - 522, 1998. DOI:10.1016/S0749-6419(98)00005-9

[9] M. Kobayashi. Analysis of deformation localization based on proposed theory of ultrasonic wave velocity propagating in plastically deformed solids. International Journal of Plasticity 26(1):107 - 125, 2010. DOI:10.1016/j.ijplas.2009.05.004.

[10] A. Kumar, T. Jayakumar, B. Raj, K. Ray. Correlation between ultrasonic shear wave velocity and Poisson's ratio for isotropic solid materials. Acta Materialia 51(8):2417 - 2426, 2003. DOI:10.1016/S1359-6454(03)00054-5

[11] H. H. Hilton, S. Yi. The significance of (an)isotropic viscoelastic Poisson ratio stress and time dependencies. International Journal of Solids and Structures 35(23):3081 - 3095, 1998. DOI:10.1016/S0020-7683(97)00357-0

[12] T. Zavadil. NDT assessment of microstructure changes of materials after heat treatment, 2009. Bachelor's thesis, CTU in Prague.

[13] T. Zavadil. The use of NDT methods for detection of microstructure changes of steels when performing residual life assessment of industrial equipment, 2012. Master's thesis, CTU in Prague. 